\title{
A New Paradigm for Adaptive Management
}

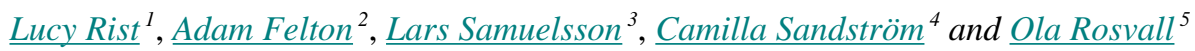

ABSTRACT. Uncertainty is a pervasive feature in natural resource management. Adaptive management, an approach that focuses on identifying critical uncertainties to be reduced via diagnostic management experiments, is one favored approach for tackling this reality. While adaptive management is identified as a key method in the environmental management toolbox, there remains a lack of clarity over when its use is appropriate or feasible. Its implementation is often viewed as suitable only in a limited set of circumstances. Here we restructure some of the ideas supporting this view, and show why much of the pessimism around AM may be unwarranted. We present a new framework for deciding when AM is appropriate, feasible, and subsequently successful. We thus present a new paradigm for adaptive management that shows that there are no categorical limitations to its appropriate use, the boundaries of application being defined by problem conception and the resources available to managers. In doing so we also separate adaptive management as a management tool, from the burden of failures that result from the complex policy, social, and institutional environment within which management occurs.

Key Words: Experimental management; experimentation; management; natural resource; participation; stakeholder; uncertainty

\section{INTRODUCTION}

Adaptive management (Holling 1978, Walters 1986) has been put forward as a way of managing natural resources in the face of uncertainty. Developed by C.S. Holling and Carl Walters, and originally termed Adaptive Environmental Assessment and Management (AEAM), this approach emphasizes the identification of critical uncertainties regarding natural resource dynamics and the design of diagnostic management experiments to reduce these uncertainties (Walters 2007). The $\mathrm{AM}$ process is a learning cycle that can be distilled down to six stages (Fig. 1). Aside from these six stages, Holling and Walters also emphasized participation of those outside the management institution in the process in order to manage conflict and increase the pool of contributions to potential management solutions (Holling 1978, Walters 1986). This emphasis acknowledged the broader social structure within which management is embedded and is an element of adaptive management that has continued to evolve producing related concepts emphasizing this focus (Table 1). Nevertheless, reduction of ecological uncertainty remains the key objective of AM specifically (Walters 2007), and it is this original meaning that is the focus of this paper.

Adaptive management (AM) continues to have broad appeal four decades after its first formal articulation (Holling 1978, Walters 1986). Yet despite its conceptual simplicity confusion persists about exactly what the approach entails, in which management contexts its use is appropriate, its application feasible, and the extent to which it has been applied successfully (Rist et al. 2013). Some have reported success where the management context is large, complex, and messy, while others claim the approach is most feasible in small-scale applications dealing with relatively simple management questions (Walters and Holling 1990, McConnaha and Paquet 1996, Johnson 1999, Simberloff 2009). 'Appropriateness', 'efficacy', and 'success' are just a few of the terms used, often interchangeably, when AM is evaluated (Gregory et al. 2006, McFadden et al. 2011). Additionally, what is considered to constitute 'success' differs with some authors referring to adherence to the cyclical AM process and others to reduced uncertainty. Thus, while there is little overall clarity one consistent message nevertheless emerges; AM is challenging to implement and appropriate in only a subset of natural resource management problems (Allen and Gunderson 2011).

There have been many commentaries on the 'failures' of AM, including the identification of specific barriers to its application (Moir and Block 2001, Allan and Curtis 2005, Walters 2007, Allen et al. 2011). However, given that interest in its use persists there is a need for clarification over what exactly is being referred to when discussing 'barriers' or 'failures'. Specifically, clarification is needed over three related, but distinct, aspects: 1) What dictates the appropriateness of AM as a method for reducing ecological uncertainty? (i.e., does experimentation represent a possible opportunity to improve management?). 2) What influences its feasibility (i.e., is it possible to do, given, for example, differing values and interests of actors and the complexities of the social, political, and institutional context in which management is embedded?), and 3) Is AM successful in that same context? (i.e., given that AM is both appropriate and feasible, did its application lead to reduced ecological

\footnotetext{
${ }^{1}$ Ecology and Environmental Science, Umeå University, ${ }^{2}$ Southern Swedish Forest Research Centre, Swedish University of Agricultural Sciences, ${ }^{3}$ Department of Historical, Philosophical and Religious Studies, Umeå University, Sweden, ${ }^{4}$ Department of Political Science, Umeå University, Sweden, ${ }^{5}$ Rosvall Forest Consulting AB
} 
Fig. 1. The adaptive management process (based on Walters [1986:9] and Holling [1978:20]). Stakeholder participation is considered central to the process and to achievement of successful natural resource management.

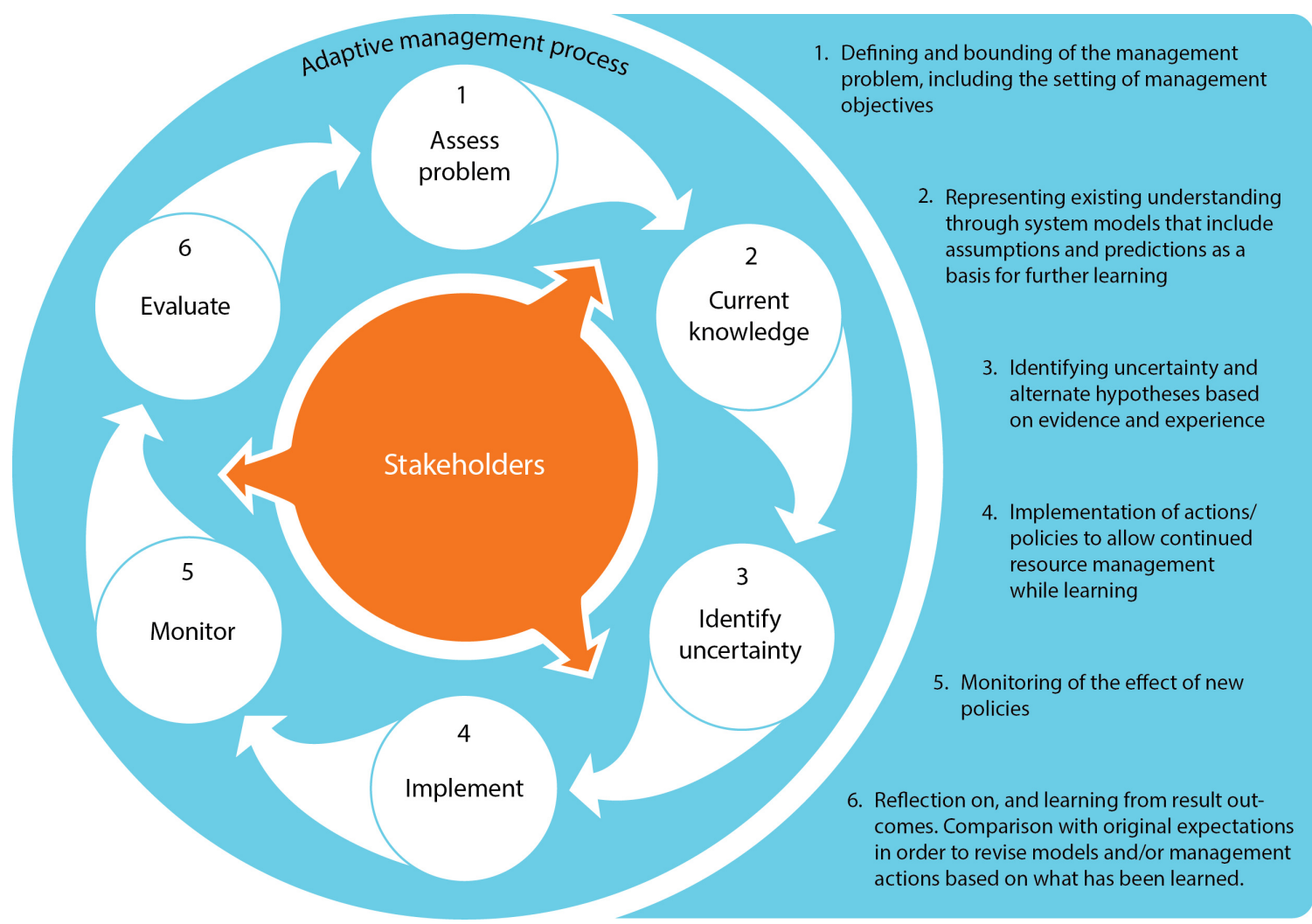

uncertainty and improved management outcomes, or did experimentation fail to reduce uncertainty, maybe as a result of external or unforeseen factors?).

We begin by outlining some of the perceived obstacles to the successful application of AM and by discussing how the confounding of general management problems with problems inherent to AM has led to undue pessimism. We then use the three questions above to structure an alternative framework for deciding when AM is appropriate, feasible, and subsequently successful. This structuring further highlights some of the prominent generalizations and misunderstandings that have contributed to confusion regarding the potential role for AM. With this new perspective on the boundaries to the use of AM we show why the pessimism present in some earlier discussions is unwarranted and in doing so present a new paradigm for thinking about the role of AM in environmental and natural resource management.

\section{PERCEIVED OBSTACLES}

Supporters and critics alike have identified many potential obstacles in applying AM including specific 'pathologies' and reasons for failure. These have included barriers relating to planning and decision-making in management, challenges encountered in management implementation, and in its subsequent evaluation (Table 2). For example, where decision makers are risk averse there tends to be a reluctance to invest in long-term management. In such cases the required action, or the outcome itself, may be anticipated to be economically or politically expensive. Thus, decision makers move ahead with small-scale experiments and miss out on opportunities to make more meaningful improvements in management and the state of the resource (Allen and Gunderson 2011).

Given these identified obstacles, particular contexts have been deemed more or less suited to AM (e.g., Gregory et al. 2006, Doremus et al. 2011) and schemes of criteria for the application of AM developed (e.g., Gregory et al. 2006, Smith 2008, Williams et al. 2009, Goodman and Sojda 2013). Some of these formulate categorical obstacles to the implementation of AM, for example the ability to engage stakeholders, amenability to relevant legal frameworks, or the ability to represent resource relationships and management impacts in models (Williams et al. 2009). Several suggest that the perceived accumulation of particular limitations in a given 
Table 1. AM-related concepts that have developed to emphasise a focus on participation or democracy in natural resource management

\begin{tabular}{ll}
\hline \hline Term & Definition \\
\hline Adaptive management & $\begin{array}{l}\text { Natural resource management conducted in a manner that purposely and explicitly aims at increasing knowledge } \\
\text { and reducing uncertainty (Holling 1978, Walters 1986). }\end{array}$ \\
Adaptive comanagement & $\begin{array}{l}\text { Merges the principles and practices of comanagement and adaptive management and explicitly links learning } \\
\text { (experiential and experimental) and collaboration to facilitate effective governance (Armitage et al. 2009). }\end{array}$ \\
Adaptive governance & $\begin{array}{l}\text { Adaptive governance refers to the dynamic structures and processes by which societies share power, and shape } \\
\text { individual and collective actions regarding the management of natural resources (Folke et al. 2005, Ostrom 2008). } \\
\text { Adaptive governance thus includes the political nature of decision-making which influences management, as well as } \\
\text { the steering and accountability mechanisms between a governing and management body (Brunner et al. 2005) }\end{array}$
\end{tabular}

management context is indicative of whether or not AM is likely to be successfully implemented (Gregory et al. 2006, Goodman and Sojda 2013, Williams et al. 2009). Thus the presence of highly controversial risks, management problems characterized by extended temporal or spatial scales, or high structural uncertainty have been judged to predispose to the likelihood of an unsuccessful application of AM (Table 2).

By identifying certain categories of management problem considered to be less amenable to the application of AM than others, the AM literature perpetuates several potentially counterproductive perspectives. Firstly, that AM is appropriate in a limited number of circumstances and that it is frequently unsuccessful. Instead, AM's success should only be evaluated where its application was both appropriate and feasible in the management context. Secondly such perspectives make the tacit assumption that uncertainties are monolithic entities. AM may not be suitable for addressing all uncertainties, however, it is arguable that many uncertainties which are problematic due to their complexity are amenable to reformulation into component and more manageable uncertainties. Thirdly such perspectives ignore the great diversity amongst actors (from small scale managers up to government administered agencies) and their associated access to vastly divergent levels of resources. By doing so such perspectives may dismiss opportunities for AM based on unjustifiable assumptions regarding management capacity. From this basis we propose a relatively simple, but potentially paradigm-shifting analogy; that AM is as applicable for natural resource management as the scientific method is for researchers. From this perspective some of the perceived obstacles to AM can, as with the scientific method, be reconsidered as obstacles of resources potentially solved by a more innovative approach to problem conception.

Below we present an alternative framework for deciding when $\mathrm{AM}$ is appropriate, feasible, and subsequently successful that builds on the implications of this analogy and outlines a new approach for deciding if AM may be useful in a certain context and how its application can be subsequently evaluated. In the discussion we return to our scientific analogy and bring these two insights together in a new paradigm for AM.

\section{A NEW APPROACH TO AM EVALUATION}

Our new approach consists of three consequent stages. Before applying AM we need to consider whether, in the first instance, it is appropriate to the management objective at hand. Secondly, whether it is actually feasible given the wider context within which management takes place. But appropriateness and feasibility of course do not guarantee success. Thus, finally, even if AM is appropriate and feasible there are still a number of ways in which the application of AM can ultimately fail to be successful. We provide a decision tree based on formulating a hierarchy of distinct questions to guide managers through these three stages (Fig. 2). Stage one deals specifically with AM as an appropriate means to reduce ecological uncertainty, stage two with AM's feasibility within a specific management context, and stage three with evaluating the success of its application. Each decision node is discussed in turn.

\section{Stage 1: Is adaptive management appropriate?}

Adaptive management of natural resources is that which purposely and explicitly decreases ecological uncertainty, learning about potential management choices through direct comparisons of their performance in practice (Holling 1978, Walters 1986). Thus, for AM to be appropriate, i.e., for it to be suitable or correct in a particular management context, ecological uncertainty must be a key obstacle for management, and it must be possible to reduce this uncertainty experimentally.

Ecological uncertainty relates to lack of knowledge about the ecological system being managed, for example about how a particular species within an area of interest may respond to changing climate or how the harvest method of a plant species affects its population structure and density. This has been named 'epistemic uncertainty' (Walker et al. 2003) or 
Table 2. Identified 'pathologies' and reasons for failure

\begin{tabular}{lc}
\hline \hline Pathology or cause of failure & Reference \\
\hline
\end{tabular}

Planning and decision making

Decision makers fail to understand the need for adaptive management

Decision makers are risk averse, reluctance to invest in long-term management, trade-off in present versus future value of management experimentation

A focus on planning and discussion with laissez faire treated as an option (action procrastination)

Insufficient attention to building shared understanding and joint decisionmaking among diverse interest groups

Tendency of scientists to overstate ability to measure complex functional relationships experimentally

Conflict and self-serving behavior impede leadership, communication and joint action

Implementation

Difficulty of conducting experiments

Implementation and monitoring are expensive, inadequate funding for the monitoring required to successfully compare the outcomes of different management options

Learning is not used to modify policy and management

Cost and delays associated with gathering information and learning

Institutional fragmentation where multiple organizations have overlapping management responsibilities

Lack of leadership and trust

Lack of stakeholder engagement

Evaluation and reflection

Scientists fail to recognize the full range of management options, belief by management agencies that a single best policy confers credibility

Surprises are suppressed

Management goals become subordinate to research interests, valuing action more than learning
Walters 2007

Allen and Gunderson 2011, Duncan and Wintle 2008, Lee 1999, Walters 1997

Keith et al. 2011, Walters 1997

Gregory et al. 2006, Feldman 2008, Allen and Gunderson 2011, Keith et al. 2011

Gregory et al. 2006

Conroy et al. 2011, Keith et al. 2011

Keith et al. 2011

Walters 2007, Johnson and Williams 1999, Walters 1997

Duncan and Wintle 2008

Lee 1999

Gregory et al. 2006, Pahl-Wostl 2006

Walters 2007, Gunderson and Light 2006

Allen et al. 2011

Gregory et al. 2006, Walters 1997

Keith et al. 2011

Lee 1999, Walters 1997 'incomplete knowledge' (Brugnach et al. 2008); we use the label ecological uncertainty. Ecological uncertainty can exist due to lack of data, unreliability of data, lack of theoretical understanding, or general ignorance. It is possible however, in many situations, to reduce such uncertainties given sufficient time and resources (a point we return to below).

Where sufficient knowledge of resource dynamics and the influence of management on those dynamics are readily available, ecological uncertainty may not be the main obstacle to management goals. Where it is rather specific political, social or institutional (rules and norms) challenges which represent the most considerable obstacles to progress in management one might conclude that AM is not appropriateit is not being applied in the correct context for which it was intended and other approaches may be more suitable. For example conventional resource management methods such as historically informed 'best practice' (Allan 2007). If, however, it is established that ecological uncertainty is a key obstacle, we must then consider if this uncertainty can be reduced through the use of structured experiments (Fig. 2).
In some cases experimentation might be challenging, for example where system manipulation would be required at a scale that precludes replication or where the time necessary for the results to become available, and for learning to therefore occur, is prohibitive. In such cases, a manager should then consider if uncertainty could be addressed with experiments that target a different or reduced combination of contributing uncertainties. This involves a process of deconstructing the management challenge and the uncertainties involved (Fig. 2). Thus, as outlined above the question of whether experiments can be used to reduce the identified uncertainty needs to be considered by managers in light of the flexibility that problem conception provides.

While some uncertainties that exist as obstacles to effective management have been judged to be too complex to be tackled with AM, these uncertainties are not monolithic entities. Uncertainties are subjectively defined aspects of any system, and thereby are readily amenable to re-interpretation and recategorization. Such re-interpretation and re-categorization enables one uncertainty to be deconstructed into its contributing uncertainties. For example, in fisheries 
Fig. 2. Decision tree for evaluating adaptive management. Evaluation begins on the left progressing towards the right in order to establish the suitability of AM application, its feasibility, and its ultimate success. Stage 1 relates solely to the goal of reducing ecological uncertainty and the appropriateness of using AM to attain that goal. Stage 2 emphasizes the need to consider the feasibility of AM in terms of resource constraints as well as the specific social, political, and institutional context of management. Alternatives to AM are likely to be conventional resource management methods and/or tools specifically intended to resolve political, social, or institutional obstacles to successful resource management. Stage 3 indicates where AM may be legitimately evaluated.

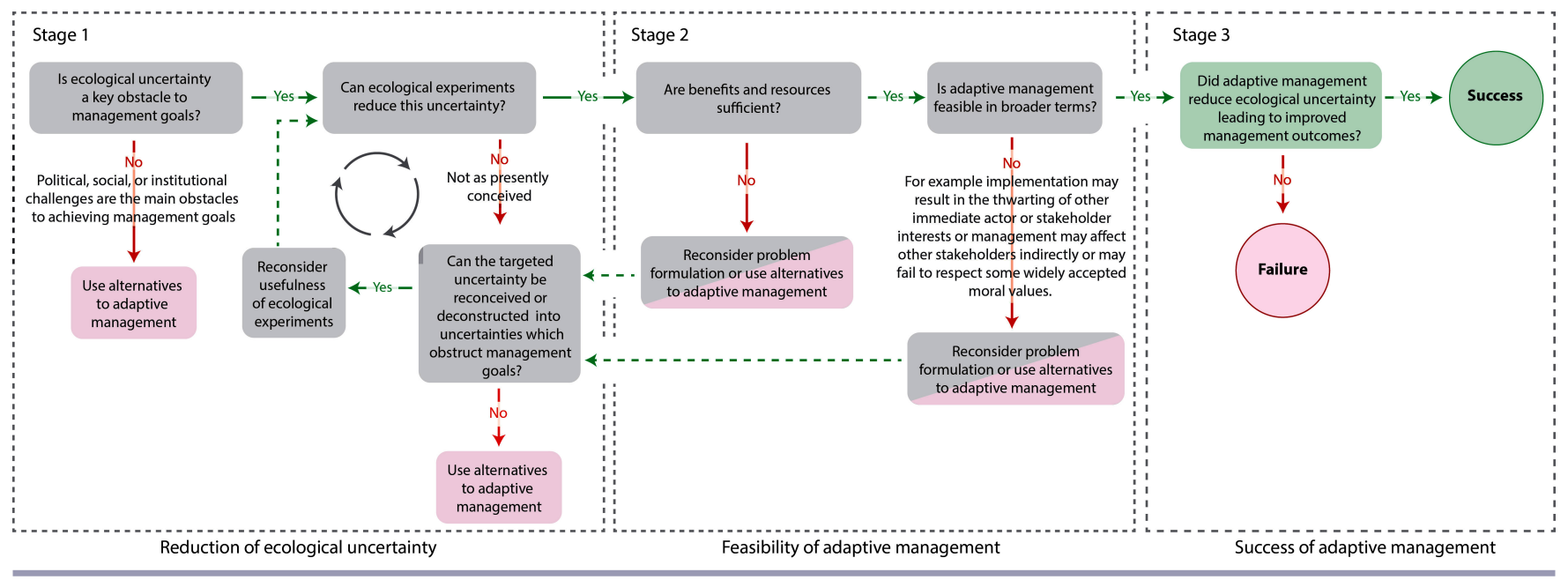

management, stock assessments are characterized by high levels of uncertainty. The total uncertainty surrounding a stock assessment can be deconstructed into that surrounding, amongst other factors, natural mortality rate, fish migration patterns, and variability in fish's vulnerability to fishing gear. Once this composite nature of uncertainties is acknowledged, it becomes clear that certain categories of problem are not, by default, any more or less appropriate for the use of AM. If ecological uncertainty is a key obstacle, AM is appropriate.

For example, climate change related uncertainties are readily characterized as complex problems involving external and variable drivers, encompassing spatial scales and delayed feedbacks (e.g., Ballantyne et al. 2012). Indeed, climate change related uncertainties have been identified as those particularly likely to be unsuitable to AM application (e.g., Norgaard et al. 2009, Williams 2011). A manager of a protected area could mistakenly characterize climate change related uncertainties as thereby lying outside the realm of appropriateness for AM application. However it is the form and nature of uncertainty that must be the starting point when considering the use of AM; rather than whether a management problem can be assigned to a specific category, for example being characterized by a short project duration, a limited spatial extent, or the absence of controversial trade-offs (Table 2).
Stage 2: Is adaptive management feasible?

Given appropriateness, other factors must then be considered before proceeding. Management resource availability, and the complexities of the wider social, political, and institutional context of management, will influence if AM is actually feasible within a given context.

Taking uncertainty reduction as a starting point, it becomes clear that the boundaries in terms of applying AM are those dictated by two key factors: the resources available for management, and management flexibility with respect to problem conception (uncertainty construction). Resource availability encompasses logistical support, expertise, and finances available to support experiments, analysis, and monitoring capacity. While it may be possible to reduce uncertainty, the benefit of doing so may be outweighed by the cost of performing the required experiments or may be unrealistic given the resources at a manager's disposal (Doremus 2011, Williams et al. 2011). We use the term resources inclusively rather than exclusively to encompass any tangible or intangible asset which is available and contributes to a successful AM outcome at the management level. Resources may therefore include knowledge, capital, equipment, land, goodwill, or personnel, to support experimentation and learning in particular, as well as the overall framework within which this takes place. We consider a resource to be available if the manager has the capacity to attain the resource without sacrificing other resources 
necessary for proceeding with AM. This then sets an upper limit on the type, or number, of uncertainties that can be effectively targeted within a given time period or spatial extent. However, we emphasize that while resource constraints may limit the scope of application they do not preclude the use of AM in an absolute way.

Continuing with the climate change example above, while it is inevitable that resource constraints will exclude the capacity of this manager to address particular climate change associated uncertainties, just as resource constraints restrict the capacity of scientists to answer particular climate change research questions, there is nevertheless ample opportunity for identifying a subset of related uncertainties that fit comfortably within the realm of appropriate AM application. This is a necessary conclusion if we accept that any seemingly monolithic uncertainty that presents an obstacle to effective management is, in fact, a complex of contributing uncertainties. Thus, whereas resource constraints may prevent a manager from using AM to assess the full range of climate change related impacts on, for example, a forest of high conservation value, this same manager may be able to use AM to assess which tree species appear most susceptible to drought, stress, or most vulnerable to wildfire.

While AM has a strong focus on uncertainty reduction it is inconceivable that decisions about resource management will be made solely on the basis of improving scientific understanding and resource availability; other factors also influence feasibility. Many of which we already know to be particularly influential in AM management contexts (e.g., Lee 1999, Walters 2007, McFadden et al. 2011). The social, political, and institutional context of management play a dominant role in assessing whether it is actually possible to 'do' AM. Additionally the value of reducing uncertainty, a key aspect, can only accurately be determined within the context provided by the values of stakeholders and how they are translated into management objectives (Doremus 2011, Williams et al. 2011).

Stakeholder involvement can readily contribute to a more successful AM outcome, as it can in the application of any other tool within a broader management process (Reed 2008). Additionally, and perhaps more specific to AM, it may aid in the reduction of ecological uncertainties where new knowledge can be contributed (Holling 1978). However, the central purpose of $\mathrm{AM}$ is the reduction of uncertainty surrounding the structure of the biological and ecological relationships that drive resource or system dynamics such that decision making is improved. Evaluating whether AM is appropriate within a particular management context must therefore focus specifically on doing just that, and not its capacity to achieve other objectives (e.g., Stringer et al. 2006). Then one can ask is AM feasible given the realities of the management context, where for example, issues such as institutional fragmentation, lack of leadership or conflict between stakeholders may indicate that it is not feasible, despite being appropriate to the particular management objective (Fig. 2).

\section{Stage 3: Was adaptive management successful?}

The third stage in evaluating AM relates to its performance following implementation. By highlighting the two previous levels it becomes clear that we can evaluate whether the application of AM was successful only where it has been applied to appropriate and feasible management examples. If one applies a method in an inappropriate context, evaluation of its success is unlikely to be meaningful. By being clear on this requirement, if application is not successful it then becomes possible to accurately attribute this to some specific factor or situation, or, importantly, to something fundamental about the method itself. Such a clarification prevents the confounding of these distinct issues when discussing causes of failure. It allows the limitations of AM as a method of uncertainty reduction, to be distinguished from implementation failures such as those resulting from institutional barriers or stakeholder conflicts which are impediments to natural resource decision-making generally and not something specific to AM (McFadden et al. 2011).

For example, stakeholder involvement is a key element of AM implementation (Fig. 1). However, the role of stakeholders has frequently been ill defined, particularly in terms of questions about whether AM should, or should not, be used. AM should be evaluated on its own merits independent of some of the failures that result from the complex policy, social, and institutional environment within which all management approaches are embedded, but to which AM has unfortunately become particularly closely associated. AM must be evaluated with respect to its ability to help meet a specific goal, i.e., the reduction of ecological uncertainty (Stage 1), that for which it was intended, and not on the basis of the failures or successes of the broader participation or governance processes within which it may be applied. In sum, it is necessary to consider independently the appropriateness of AM as a means of reducing ecological uncertainty, from its feasibility in a specific management context, and ultimately its success as a process via which additional goals (for example, participation or democracy) may be achieved.

\section{DISCUSSION}

Many pathologies or barriers to AM previously identified have been overstated or are not, in fact, specific to AM at all, but rather are challenges faced in management implementation generally (Rist et al. 2013). When evaluating success there is thus a need to differentiate clearly between where AM was not appropriate to the specific management goals, or it was not feasible i.e., it was unlikely to work given the wider management context, or if despite being appropriate and feasible it still failed to improve management outcomes by 
reducing ecological uncertainty. Real world assessments of the value of experimentation within a management framework can then be made accurately and we can avoid the risk of conflating cases of inappropriate application with those where we do in fact have an opportunity to evaluate AM.

We have argued that AM is as applicable for natural resource management as the scientific method is for researchers. When stated that AM isn't suited to large complex problems, some authors are effectively saying that we can't use experiments to address large complex problems; clearly this is not the case. By specifically defining the number or type of uncertainties to be reduced the potential trade-off is highlighted, with increasingly complex management problems only suitable for $\mathrm{AM}$ where there is a corresponding reduction in the number or types of uncertainties considered and a corresponding increase in the resources available. It may then be possible to use AM in some challenging management contexts, but only if (for instance) a less complex aspect of uncertainty is targeted, and perhaps a significant amount of management resources are available. The issue may be better framed in terms of a simple trade-off; more complex natural resource problems can be handled by reducing the number of uncertainties targeted and/or by increasing the resources dedicated to solving the problem. This is the basis for a new paradigm that recognizes that there are no categorical obstacles to the implementation of AM, but rather specific limitations in terms of resources and managerial flexibility in problem conception. AM emerges as a potentially valuable tool in the toolbox of many environmental managers.

Our-proposed method for AM evaluation thus provides a clear framework for deciding when AM is appropriate, feasible, and subsequently for assessing if its implementation is successful. This framework benefits from a reflection on the earlier work on barriers and failures that we have critiqued, specifically by helping to inform responses along the decision tree. Some of the barriers and pathologies listed in Table 2 are helpful considerations for the decision tree, while others are related to the challenges encountered in management more broadly, rather than being specific to AM. For example, a lack of leadership and trust has been frequently cited as a potential pathology or cause of failure. In stage 1 , in many contexts this could represent a major obstacle that overshadows ecological uncertainty or in stage 2 it might be part of the broader context that could limit the feasibility of applying AM. In contrast, other barriers reportedly encountered during the implementation phase, such the difficulty of conducting experiments, can clearly be seen to be resolvable with use of the new framework.

\section{CONCLUSION}

$\mathrm{AM}$ as originally envisioned was developed primarily as a means of reducing ecological uncertainty with additional goals of bridging interdisciplinary gaps among scientists and managers, and of acting as a vehicle for participation of those outside the management institution. However, it has since become increasingly influenced by, and to some extent coopted by, discussions focusing on participation and institutional failures. As a result, questions regarding AM's appropriateness have become somewhat confused; issues of AM's technical ability to aid in reaching desired management goals (via the reduction of ecological uncertainty) have been mixed with questions of, for example, its ability to lead to more inclusive and democratic management. Both goals are important but they are distinct and must be recognized as such for the further evaluation and development of AM, as well as for other approaches in natural resource management.

Implementation of any management tool, AM is just one, takes place within a broader management framework, itself embedded within a social, political, and institutional context. Decisions about implementation must therefore be made in the context of broader considerations. Management and governance invariably involve trade-offs, those between different stakeholder objectives, between risk and productivity, or between short-term and long-term goals. This new AM paradigm thus must be set in the context of improved institutional structures and governance processes in order to deal with these choices (Table 1). Of much promise in this respect are both Adaptive comanagement and Adaptive governance (Folke et al. 2005, Armitage et al. 2009). However, in doing so we must distinguish between the goal of ecological uncertainty reduction via the use of experimentation in management, and broader goals and processes, for example those of sustainability, participation or democracy. Hence, a more structured approach to discussion of the utility of AM is needed where the challenges of the complex policy, social, and institutional environment within which all management occurs are no longer conflated with evaluations of AM appropriateness, feasibility, success, or failure.

Responses to this article can be read online at: http://www.ecologyandsociety.org/issues/responses. php/6183

\section{Acknowledgments:}

The research was funded through Future Forests, a multidisciplinary research programme supported by the Foundation for Strategic Environmental Research (MISTRA), the Swedish Forestry Industry, the Swedish University of Agricultural Sciences (SLU), Umea University, and the Forestry Research Institute of Sweden. We are grateful to two anonymous reviewers whose comments and reflections improved the manuscript. 


\section{LITERATURE CITED}

Allan, C., and A. Curtis. 2005. Nipped in the bud: Why regional scale adaptive management is not blooming. Environmental Management 36:414-425. http://dx.doi. org/10.1007/s00267-004-0244-1

Allan, C. 2007. Adaptive management of natural resources. Pages 1-6 in A. L.Wilson, R. L. Dehaan, R. J.Watts, K. J. Page, K. H. Bowmer, and A. Curtis, editors. Proceedings of the 5th Australian Stream Management Conference. Australian rivers: making a difference. Charles Stuart University, Thurgoona, New South Wales.

Allen, C. R., and L. H. Gunderson. 2011. Pathology and failure in the design and implementation of adaptive management. Journal of Environmental Management 92:1379-1384. http:// dx.doi.org/10.1016/j.jenvman.2010.10.063

Allen, C. R., J. J. Fontaine, K. L. Pope, and A. S. Garmestani. 2011. Adaptive management for a turbulent future. Journal of Environmental Management 92:1339-1345. http://dx.doi. org/10.1016/j.jenvman.2010.11.019

Armitage, D. R., R. Plummer, F. Berkes, R. I. Arthur, A. T. Charles, I. J. Davidson-Hunt, A. P. Diduck, N. C. Doubleday, D. S. Johnson, M. Marschke, P. McConney, E. W. Pinkerton, and E. K. Wollenberg. 2009. Adaptive co-management for social-ecological complexity. Frontiers Ecology and Environment 7:95-102. http://dx.doi.org/10.1890/070089

Ballantyne, A. P., C. B. Alden, J. B. Miller, P. P. Tan, and W. C. White. 2012. Increase in observed net carbon dioxide uptake by land and oceans during the past 50 years. Nature 488:70-72. http://dx.doi.org/10.1038/nature11299

Brugnach, M., A. Dewulf, C. Pahl-Wostl, and T. Taillieu. 2008. Toward a relational concept of uncertainty: about knowing too little, knowing too differently, and accepting not to know. Ecology and Society 13(2):30. [online] URL: http:// www.ecologyandsociety.org/vol13/iss2/art30/

Brunner, R. D., T. A. Steelman, L. Coe-Juell, C. M. Cromley, C. M. Edwards, and D. W. Tucker. 2005. Adaptive Governance: Integrating Science, Policy, and Decision Making. Columbia University Press, New York. http://dx.doi. org/10.1111/j.1468-0491.2006.00333_1.X

Conroy, M. J., M. C. Runge, J. D. Nichols, K. W. Stodola, and R. J. Cooper. 2011. Conservation in the face of climate change: the roles of alternative models, monitoring, and adaptation in confronting and reducing uncertainty. Biological Conservation 144:1204-1213. http://dx.doi.org/10.1016/j.biocon.2010.10.019

Doremus, H. 2011. Adaptive Management as an Information Problem. North Carolina Law Review 89:1455-1495.

Doremus, H., W. L. Andreen, A. Camacho, D. A. Faber, R. L. Glicksam, D. D. Goble, B. C. Karkkainen, D. Rohlf, A. D. Tarlock, S. B. Zellmer, S. Campbell Jones, and Y. Huang.
2011. Making good use of adaptive management. Center for Progressive Reform White Paper No. 1104. [online] URL: http://papers.ssrn.com/sol3/papers.cfm?abstract id=1808106

Duncan, D., and B. A. Wintle. 2008. Towards adaptive management of native vegetation in regional landscapes. Pages 1-7 in C. Pettit, W. Cartwright, I. Bishop, K. Lowell, D. Pullar, and D. Duncan, editors. Landscape Analysis and Visualisation. Spatial Models for Natural Resource Management and Planning. Springer-Verlag GmbH, Berlin. http://dx.doi.org/10.1007/978-3-540-69168-6 9

Feldman, D. L. 2008. Barriers to adaptive management: lessons from the Apalachicola- Chattahoochee-Flint compact. Society and Natural Resources 21:512-525. http://dx.doi. org/10.1080/08941920801905344

Folke, C., T. Hahn, P. Olsson, and J. Norberg. 2005. Adaptive governance of social-ecological systems. Annual Review of Environment and Resources 30:441-473. http://dx.doi. org/10.1146/annurev.energy.30.050504.144511

Goodman, D., and R. S. Sojda. 2013. Applying advanced technologies for adaptive management and decision support in natural resources. Montana State University. [online] URL: http://www.esg.montana.edu/esg/adaptive_mgmt_1.html

Gregory, R., D. Ohlson, and J. Arvai. 2006. Deconstructing adaptive management: criteria for applications to environmental management. Ecological Applications 16:2411-2425. http://dx.doi.org/10.1890/1051-0761(2006)016[2411:DAMCFA] 2.0.CO;2

Gunderson, L., and S. S. Light 2006. Adaptive management and adaptive governance in the everglades ecosystem. Policy Science 39:323-334. http://dx.doi.org/10.1007/s11077-006-9027-2

Holling, C. S. 1978. Adaptive Environmental Assessment and Management. Chichester, UK: John Wiley and Sons.

Johnson, B. L. 1999. The role of adaptive management as an operational approach for resource management agencies. Conservation Ecology 3:8. [online] URL: http://www. consecol.org/vol3/iss $2 /$ art8

Johnson, F., and K. Williams. 1999. Protocol and practice in the adaptive management of waterfowl harvests. Conservation Ecology 3:8. [online] URL: http://www.consecol.org/vol3/ $\underline{\text { iss } 1 / \operatorname{art} 8}$

Keith, D. A., T. G. Martin, E. McDonald-Madden, and C. Walters. 2011. Uncertainty and adaptive management for biodiversity conservation. Biological Conservation 144:1175-1178. http://dx.doi.org/10.1016/j.biocon.2010.11.022

Lee K. N. 1999. Appraising adaptive management. Conservation Ecology 3:3. [online] URL: http://www. consecol.org/vol3/iss $2 /$ art3 
McConnaha, W.E., and P. J. Paquet. 1996. Adaptive strategies for the management of ecosystems: the Columbia River experience. American Fisheries Science Symposium $16: 410-421$.

McFadden, J. E., T. L. Hiller, and A. J. Tyre. 2011. Evaluating the efficacy of adaptive management approaches: Is there a formula for success? Journal of Environmental Management 92:1354-1359.

Moir, W. H., and W. M. Block. 2001. Adaptive management on public lands in the United States: Commitment or rhetoric? Environmental Management 28:141-148.

Norgaard, R. B., G. Kallis, and M. Kiparskya. 2009. Collectively engaging complex socio-ecological systems: reenvisioning science, governance, and the California Delta. Environmental Science and Policy 12:644-652. http://dx.doi. org/10.1016/j.envsci.2008.10.004

Ostrom, E. 2008. The challenge of common-pool resources. Environment 50:8-20. http://dx.doi.org/10.3200/ENVT.50.4.8-21

Pahl-Wostl, C. 2006. The importance of social learning in restoring the multifunctionality of rivers and floodplains. Ecology and Society 11(1):10. [online] URL: http://www. ecologyandsociety.org/vol11/iss 1/art10

Reed, M. S. 2008. Stakeholder participation for environmental management: A literature review. Biological Conservation 141:2417-2431. http://dx.doi.org/10.1016/j.biocon.2008.07.014

Rist, L., B. M. Campbell, and P. Frost. 2013. Adaptive management; where are we now? Environmental Conservation 40:5-18.

Simberloff, D. 2009. Moving beyond strawmen and artificial dichotomies: adaptive management when an endangered species uses an invasive one. Journal of Agricultural and Environmental Ethics 22:73-80. http://dx.doi.org/10.1007/ s10806-008-9126-5

Smith, A. 2008. Defining Adaptive Management in the BC Ministry of Forests and Range. Link 10:12-14, FORREX Forest Research Extension Partnership. BC Canada.

Stringer, L. C., A. J. Dougill, E. Fraser, K. Hubacek, C. Prell, and M. S. Reed. 2006. Unpacking "participation" in the adaptive management of social-ecological systems: a critical review. Ecology and Society 11(2):39. [online] URL: http:// www.ecologyandsociety.org/vol11/iss2/art39

Walker, W. E., P. Harremoës, J. Rotmans, J. P. van der Sluijs, M. B. A. van Asselt, P. Janssen, and M. P. Krayer von Krauss. 2003. Defining uncertainty. A conceptual basis for uncertainty management in model based decision support. Integrated Assessment 4:5-17. http://dx.doi.org/10.1076/iaij.4.1.5.16466

Walters, C. J. 1997. Challenges in adaptive management of riparian and coastal ecosystems. Conservation Ecology 1:1. [online] URL: http://www.consecol.org/vol1/iss2/art1

Walters, C. J. 1986. Adaptive Management of Renewable Resources. Macmillan, New York.

Walters, C. J. 2007. Is Adaptive Management Helping to Solve Fisheries Problems? Ambio 36: 304-307.

Walters, C. J., and C. S. Holling. 1990. Large-scale management experiments and learning by doing. Ecology 71:2060-2068. http://dx.doi.org/10.2307/1938620

Williams, B. K., R. C. Szaro, and C. D. Shapiro. 2009. Adaptive Management: The U.S. Department of the Interior Technical Guide. Adaptive Management Working Group, U.S. Department of the Interior, Washington, DC.

Williams, B. K. 2011. Adaptive management of natural resources: framework and issues. Journal of Environmental Management 92:1346-1353. http://dx.doi.org/10.1016/j. jenvman.2010.10.041

Williams, B. K, M. J. Eaton, and D. R. Breininger. 2011. Adaptive resource management and the value of information. Ecological Modelling 222:3429-3436. http://dx.doi.org/10.1016/ j.ecolmodel.2011.07.003 